\title{
Relating nursing theory to students' life experiences
}

\section{S Dbwie and C Park}

Nursing is a dynamic field involving an interaction between scientificresearch and human need. Theoretical discussions often involve a complex of issues which are difficult to explore adequately in a typical lecture. This paper presents a teaching method which is highly interactive, moving students far beyond rote memorisation tow ard a deeper understanding of both the theory and practice of nursing. Numerous examples are given of the technique's application.

What instructor doesn't yearn for a highly interactive class with students deeply engaged in the dilemmas of nursing practice and actively participating in dass discussion. Yet, a problem common to many nursing courses is that the subject content deals with complex situations which are an interaction between values and procedures based on scientific research. To make matters worse it is usually taught to students between the ages of 18 and 21 years. They generally have little in the way of experience with life or with the specialneeds of patients in clinical situations. Consequently, the lecture can become a somewhat abstract collection of statistics and nursing procedures about situations beyond the students' comprehension. As such, students are unlikely to participate actively and learning often focuses on rote recall of fact.

This paper describes an approach to teaching nursing courses that is designed to address these issues and to elicit widespread voluntary participation in class discussion. It is based on a

Sandra Dowie M A Jnstruction Design Consultant Caroline Park BN MEd Assistant Professor, Faculty of Nursing, University of Alberta, Edmonton, Canada Manuscript accepted 9 November 1987 question-asking approach based on Andrery's (1980) work and subsequent papers by Rasmussen (1984) integrating group methods and experienced-based learning.

After briefly discussing these instructional approaches, a series of questions specific for the particular nursing lecture will be presented as an example of an application of the method. In this case, the focal topic is childbirth. However, the approach would be suitable for a wide variety of areas concerning nursing practice.

\section{QUESTIONING STRATEGIES}

Andrews (1980) studied questions asked by university instructors across a variety of institutions, disciplines, course types and course levels. H e found that the number of voluntary student responses was dependent on four characteristics of the questions:

1. Whether they required higher level cognitive characteristics such as analysis, evaluation, or synthesis (Bloom 1956) as opposed to memory-level answers or simple rephrasing of instructional materials. 
2. Whether they were divergent (e.g., suggesting more than one answer is acceptable) as opposed to convergent.

3. Whether they were unitary (single questions) as opposed to multiple.

4. Whether they were structured (giving students sufficient directions, contexts, or guidelines to enable them to understand how they might approach an answer) as opposed to wide open or unstructured.

Andrews and other investigators have reported that few instructors utilise other than convergent, memory-level questions and that . student response rates are generally low.

\section{GROUP TECHNIQUE}

Rasmussen (1984) has shown that voluntary participation in class discussions can also be facilitated by using a modification of Van de Ven and Delbecq's (1974) Nominal Group Technique. A three-step procedure is used:

1. An Andrew-type question is posed to the class as a whole.

2. Students are asked to share their thoughts with the person(s) sitting nearest them. A time limit of a minute or two dependingon the question difficulty is set.

3. Volunteers are asked to answer the questions or the class is polled to provide a sample of opinion on the questions.

The movement to dyads or triads takes little time and can be done without any special seating arrangement, even fixed-seatingfacing forward. It evokes divergent ideas and makes the class discussion more provocative than the typical method of posing a question to the class as a whole and immediately calling for answers. Threat and uncertainty are reduced by providing a social comparison process (Festinger 1954; Wheeler 1970). Thus, students are more willing to voluntarily share their thinking in the larger class discussion. Perhaps even more important than discussion in the whole class, the group structure coupled with well structured questions promotes active intellectual engagement in dyads as opposed to the passive, note-taking stance adopted by students in many lecture situations. This method has been' effectively used in a variety of contexts with classes ranging in size up to 150 students.

\section{Questions for a specific nursing application}

These instructional components (question structure and use of small groups) can be used to facilitate intellectual engagement and voluntary participation in any Iecture. To provide an example of the method's application, a series of questions are shown below which were used in several classes for first year nursing students enrolled in a university course in developmental psychology. The topic of the day was on family centred childbirth.

The learning goals for the seminar were:

1. To familiarise students with medical issues and nursing procedures in obstetric practice.

2. Toexamine how theattitudesand values of nurses and other medical practitioners interact with those of patients to produce desirable medical outcomes.

The latter goal was introduced to demonstrate the point made by Tanner (1983) who cites attitudes and values as clinician variables which infuence both the process and outcome of clinicaljudgment.

To attain these learning goals. and the additional objective of high levels of participation, the sequence of questions was based on a series of personal situations with which students would be able to identify and that were parallel to situations that they might encounter in an obstetrical ward.

The first issue that we wished to have them consider was how values and feelings about privacy might interact with the various kinds of authority relationships found on a medical ward and might affect medical progress of the patient. Todo so, we stated this objective, presented the following situation, and asked several questions about it: 
Silualion 1 Imagine being in your High School locker room. Time is running a bit lute and most of you know one another quite well and are changing in the open area. Your Physical Education instructor, an older woman about to retire, comes in and in a very strong voice says, 'IVhy aren't you girls in the changing rooms? Don't jou have any "needsfor privacy.'

Question $I$ Has anything like this ever happened toyou?

Question 2 How did youfeel emotionally?.

Question 3 What would bejour reactions tojour instructor?

Question 4 Would your reactions interfere in anyway with your sports activities on that day?

Question $5 \quad$ How should the instructor have acted in this situation? Did she behave properly?

The situation' and related questions ask students to focus on a situation with which they could easily and personally identify. The key issues are differing values about personal privacy and reactions to the imposition of authority to resolve such issues.

The large majority of the class were female students so many ofthe questions were slanted to their point ofview. When necessary, equivalent, - male-oriented alternatives were suggested.

The situations and questions were presented on an overhead projector so that they could easily be read by the students (an alternative is to put them on a single page handout). In exploring the questions, students were required to go beyond a rote recitation of text answers. A higher level of thinking was required. Questions were uncovered one at a time so that the students are not overwhelmed (thus making it a series of single questions, rather than a multiple question). The instructor made it clear that there will probably be different reactions on the part of students to the questions and the purpose is to explore those different reactions. This indicated that the question is divergent (more than one answer possible) and gave the students sufficient structure within which to consider their answers.
Thus, Andrew's four criteria for constructive questioning were fulfilled.

In the class in which we asked these questions the students were instructed to take a minute or so to discuss their experiences and thoughts with the person(s) sitting nearest them. The reaction to these first few questions was immediate and energetic. When the noise level died down, opinions were solicited. Reactions ranged from strong feelings of shame and resentment towards the hypothetical instructor. Many students could recall such situations, and most felt that the instructor had unfairly imposed her values and that the sport period activity would be harmed as a consequence of her actions.

The nursing instructor's role in handling these questions was to draw outand highlight the range of responses. The instructor was also able to point out that such reactions on the part of students in the locker room was likely to represent the range of reactions of patients on a nursing ward to the behaviour and values of nurses and physicians.

Question 1 was designed to give students something easy to talk about and to serve as an icebreaker at the start of the class. It also was designed to enable students to better empathise with the patient in the following situation taken from an interview with a nurse on an obstetrical ward.

situation 2 This is a recent scene that occurred in one of our local hospitals. A woman - has been in labourfor 8 hours and is in a Birlhing Room. She is extremely hot and uncomfortable. She has stripped of her gown and is lying nude on the bed. Her physician comes in, picks up a sheet, and, without saying anything, drapes it over her. You, the nurse, sland by and do nothing.

Question I How is this similar to the locker room situation?

Question 2 How might the womanfeel about the doctor ... about you ... about herself?

Question $3 \quad$ Hour might his affect the woman in her birthing process and in herfuture interactions 'with you and her physician? 
Again, and for all ensuing questions, the students are asked to take a minute or so to discuss the question with the persons sitting nearest them. Following this, volunteers are asked to share their opinions, As with Situation 1 students suggested a range of reactions, from guessing that the patient will feel that her rights have been violated to feeling shame about the implied criticism from her physician and anger towards both you and the physician. Some predicted that the patient's feelings will be affected for some time after the incident, just as theirs might 'have been 'on the sport field after being chastised by the Physical Education instructor.

Our next instructional goal was to explore the authority dilemmas occurring from differences between nurse, physician, and patient values.

Situation 3 Youare buck in the locker room Your
instructor has suggested that you go
intoyour privalechange roomandget
out to the playing field as soon as
possible. She then leaves the room.

Question I What do you do? Go in or change where you are?

Question 2 Would those of you whofeel that the instruclor acted ufairly do anything about it, in a formal or informal way?

In response to this situation, some students reported that they would probably go into the lockers, while others would remain in the change area. Few indicated that they would take any steps to rectify the unfair imposition of values and authority by talking to the instructor or by raising the issue with higher authorities. Some students stated that they have taken action in such situations (e.g. by raising the issue with their instructor). However, most indicated that they haven't done anything at such times and even those that have indicated that their actions led to negative repercussions down the line. Thus, students are confronted with the fact that authority and power issues will sometimes cause them to want to act in ways that may not be consistent with their personal beliefs.

Situation 3 was designed to be a lead in to Situation 4, which was focused on the dilemmas presented to nurses by the conflicting sources of authority and values in hospital wards.

Siluation 4 Minutes later the woman says, Ifeel terrible I'm too hot!' The doctor has left and probably will not come through again unil you call him.

\section{Question 1 iWhat doyou do8}

When polling for this question, the instructor . might act as devil's advocate if answers seem to be too pat, denying the reality of a nuse's position of power within' the hospital by reminding them of their own lack of'response when confronted unfairly by the Physical Education instructor. The purpose of relating the issue of the nurse's power to act to one in which students are typically reluctant to use their own power to act, is to get students to identify rather than make a simplistic assessment of what a nurse should or should not do.

The next questions follow the same pattern as the initial ones. They serve to provide more depth to the exploration of the psychological - issues inyolved in the management of childbirth. At this point in our Iesson plan, we wished to shift the discussion to issues related to the need for emotional privacy and constructive support.

Situation 5 You have just broken off with your boyfriend and its the middle of the school day. You can't control your crying.

Question $1 \quad$ Wheredoyou wanl to go?

Question 2 Whodoyou want tube with, if anyone?

Question 3 Haw do you react if a friend of yours says, 'Fypuit the crying. He wasn't good enough foryou anyway.'

Immediately after this discussion, the following parallel situation is presented:

Situation 6

A woman is about to deliver herfirst child and is in a strange hospital. She has only briefly met the nursing staff. It's very noisy and strangers are constantly coming and going. Her physician isn't there and probably will not arrive until minutes before the birth.

Question I How doesshefeel? 
wishes and are a good reflection of the complexity of real choice making in our medical system.

The preceding discussion provides a compelling introduction to the issues of safety and alternative birthing practices. Statistics concerning controversial practices such as episiotomies, cesareans, vagina! births after cesareans, etc. don't seem as remote and irrelevant. There is an increased likelihood for viewing the complexity of safety v.s. emotional bias realistically. By relating theoretical content to the students' own emotional experience (real and conjectured), the students seemed to become more open intellectually and psychologically to a variety of humanistic and medical issues. This is a crucial exercise in all areas of nursing at a time when there is increasing pressure for the profession to be more responsive to the individual needs of patients.

In sum, lectures may be designed around these concepts:

Andrew-type questions, short intervals, small group discussion and real life issues. These are combined to promote increased self-understanding and a more thoughtful approach to nursing care. This process is in itself a dynamic and exciting one for both the instructor and the students.

\section{Acknowledgement}

We would like to acknowledge the valuable assistance that Florence Ross, RN gave us in providing realistic situations based on her ward experience.

\section{References}

Anderson Sandra Van Dam, Simkin Penny 1981 Birth through children's eyes. Pennypress: Seatile

Andrews $\mathbf{M}$ 1980 The verbal structure of teacher questions and its impact on class discussion. POD Quanlery 3.4: 129-163

Bloom B S (Ed) 1956 Taxonomy of educational dojectives: Cognitive and affective domains. David Mickay: New York

Festinger L 1954 A theory of social comparison. Human Relations 7: 117-140

Merrill MI D, Reigeluth C MI, Faust GW 1979 The instructional quality profile: A curriculum evaluation and design tool. In H F O'Neí. Jr (Ed) Procedures for instructional systems development. Academic Press: New York

Merrill M D, Tennyson R D 1977 Teaching concepts: An instructionaldesign guide. Educational Technology Publications: Englewood Cliffs, N.J.

Rasmussen R V 1984 Practical discussion techniques for educators of adults. AACEJournal 12, 2; 38-47

Tanner C A 1983 Research on clinicaljudgement. In If L Holtemer (ed) Review of Research in Nursing Education. Slack: New Jersey

Van de Ven A H. Delbecq A L 1974The effectiveness

-of nominal, delphi and interacting group decisionmaking processes. Academy of Management Journal 17, 4: 605-621

Wheeler L I970 Interpersonal influence. Allyn \& Bacon: Boston 
Question2 How might this affect her ability to relax and give birlh?

Question 3 Who ore her most important support persons?

Question 4 How might she react if you, the nurse, say 'Come on, the pain isn't as bud as all that, is it?'

These questions are designed to enable the students to understand the birthing experience from a personal perspective.

\section{INSTRUCTOR INPUT}

The main instructional method to this point in the discussion has been instructor questioning. Lecture points are of course necessary. In fact, students expect the instructor to operate primarily in the lecture mode. However, instructors will find the greatest receptivity to their lecture when the students already have a vested interest because they have formed their own opinions on the ideas being discussed. Throughout the preceding discussion of situations, the instructor is serving as discussion facilitator, drawing out different ideas. She is also making points and helping the students organise their ideas into a conceptual framework consistent with medical practice. For example, at this point in the discussion, she might summarise what has been said by pointing out that:

I. We can expect patients to come to us with a wide range of values.

2. These values will not always be consistent with our own values.

3. T h e way we deal with these differences in values will almost certainly affect the patient's feelings and subsequent medical progress.

4. As nurses, we sometimes have to manage these conflicting value positions from a position of lower authority, (e.g., the doctor may impose his or her authority without soliciting our opinion).

5. In other cases, we will act as the authority. When we recognise that a value difference is affecting the way we deal with a patient, we would do well to ask ourselves whether imposing our value position stems from medically sound premises or simply from our own biases which are not related to and may interfere with patient rights and medical progress.

Having drawn aut several points by having students relate to persona1 experiences that are parallel to experiences they might have or witness in a nursing ward, the question sequence shifts toexploring issues on a more abstract level.

Question 6 Aside from ihe issue of safely, whose values are most important in the birthing question ...

- the doctors's

- the nurse's

- thewoman's

- her husband's?

At this point, students may blithely agree that 'of course' what is most important are the concerns of the birthing mother provided that what she wants is safe. Question 7 introduced more conflict into the discussion than the preceding questions.

\section{Situation 7 A woman wants her young child to be present at her birth in the birthing room of your hospital.}

\section{Question: What do you think about this?}

Ignore the fact that presently it's against hospital policy . . .its only been in the last 15 years that husbands have been able to attend birthsin Edmonton.

The choice to have siblings at birth is a highly emotional topic which serves to catalyse the preceding discussion. It is a good illustration of the issue ofsafety being coloured by the values of the medical profession rather than research evidence. There is no sound data that indicates that children are damaged by attending births. There are accounts of thesuccess and richness of birthing programs which do involve siblings (Anderson 1981). Confronted with this information students may talk about the lack of space, children getting in the way, the long times involved with birth, etc. These are problems that go beyond simply complying with the mother's 